\title{
Effect of solvents on the crystal formation of poly(vinylidene fluoride) film prepared by a spin-coating process
}

\section{Takashi Nishiyama, Takayuki Sumihara, Eriko Sato, Hideo Horibe}

\begin{tabular}{|c|l|}
\hline Citation & Polymer Journal, 49(3); 319-325 \\
\hline Issue Date & $2016-12-21$ \\
\hline Type & Journal Article \\
\hline Textversion & author \\
\hline Relation & $\begin{array}{l}\text { This is a post-peer-review, pre-copyedit version of an article published in Polymer } \\
\text { Journal. The final authenticated version is available online at: } \\
\text { https://doi.org/10.1038/pj.2016.116 }\end{array}$ \\
\hline DOI & $10.1038 /$ pj.2016.116 \\
\hline
\end{tabular}

\author{
Self-Archiving by Author(s) \\ Placed on: Osaka City University
}

NISHIYAMA T., SUMIHARA T., SATO E., \& HORIBE H. (2017). Effect of solvents on the crystal formation of poly (vinylidene fluoride) film prepared by a spin-coating process. Polymer Journal. 49, 319-325. 


\section{Effect of solvents on the crystal formation of poly(vinylidene fluoride)}

\section{film prepared by a spin-coating process}

Takashi Nishiyama $^{\mathrm{a}}$, Takayuki Sumihara ${ }^{\mathrm{a}}$, Eriko Sato ${ }^{\mathrm{a}}$ and Hideo Horibe ${ }^{\mathrm{a} *}$

${ }^{a}$ Graduate School of Engineering, Osaka City University, 3-3-138 Sugimoto,

Sumiyoshi-ku, Osaka 558-8585, Japan

*Correspondence. Tel. and Fax: +81-6-6605-2981

E-mail: hhoribe@a-chem.eng.osaka-cu.ac.jp

Running head: Effect of solvents on PVDF crystal formation 


\section{Abstract}

The effect of the solvent evaporation rate and solvent type on the crystal formation of poly(vinylidene fluoride) (PVDF) prepared by spin-coating was evaluated over time. In the much-solvent-remaining state, the crystalline phase of PVDF changed in the order of $\alpha, \gamma$, and $\beta$ with the increasing dipole moment of the solvent. In the almost-all-solvent-evaporated state, the crystalline structure of PVDF/hexamethylphosphoramide with a higher dipole moment was dominantly dependent on the evaporation rate and varied in the order of $\beta, \gamma$, and $\alpha$ with the increasing solvent evaporation rate. However, PVDF/triethyl phosphate, having a lower dipole moment, always formed the $\alpha$ phase, regardless of the evaporation rate. The PVDF $\alpha$ phase in the concentrated solution state is difficult to transform into the $\beta$ and $\gamma$ phases because the potential energy of each PVDF crystalline phase increases in the order of $\alpha, \gamma$, and $\beta$. The PVDF crystalline phase in the spin-coating method is strongly affected by both the polymer-solvent electrostatic interactions and the evaporation conditions. From the results of the crystal transition behavior, it was experimentally supported that the potential energy of the PVDF crystalline structure increases in the order of $\alpha, \gamma$, and $\beta$.

Keywords: poly(vinylidene fluoride) / crystalline structure control / spin-coating / 


\section{Introduction}

Poly(vinylidene fluoride) (PVDF) is well known as a ferroelectric polymer, and the crystalline structures are considered to be present in at least four types: the $\alpha, \beta, \gamma$ and $\delta$ phases. The PVDF $\beta$ phase (form I) is an all-trans planar zigzag conformation (TTTT), the PVDF $\alpha$ phase (form II) is a trans-gauche twist conformation (TGTG'), the PVDF $\delta$ phase (form IV) is a different packing structure of the PVDF $\alpha$ phase, and the PVDF $\gamma$ phase (form III) is an intermediate conformation of the PVDF $\beta$ and $\alpha$ phases (TTTGTTTG'). ${ }^{1,2)}$ The ferroelectric characteristics of PVDF are caused by the polarized structure between hydrogen $(\delta+)$ and fluorine $(\delta$-), and the $\beta$ phase possesses superior ferroelectric properties because of the well-oriented polarized structure of its all-trans planar zigzag conformation. The total potential energy of the intra- and intermolecular interactions of the PVDF $\beta$ phase is higher than that of the PVDF $\alpha$ phase, and thus, the PVDF $\alpha$ phase is more stable than the PVDF $\beta$ phase in terms of the potential energy. The PVDF $\beta$ phase is typically prepared by a poling process while stretching a PVDF $\alpha$ phase film. ${ }^{3)}$ The control of PVDF crystalline structures has attracted much attention. $^{4-12)}$

Previously, it was reported that PVDF crystalline structures were prepared separately by the solvent-casting method with different solvents. ${ }^{13)}$ Hexamethylphosphoramide 
(HMPA), acetone, and dimethylacetamide (DMAc) were utilized in solvent-casting to prepare PVDF $\beta, \alpha$, and $\gamma$ phase crystalline structures, respectively. We focused on the differences in solvent boiling points and considered the relationship between the PVDF crystalline structure and solvent evaporation rate. Generally, the PVDF $\alpha$ phase is more kinetically stable than the $\gamma$ and $\beta$ phases, while the $\beta$ phase is more thermodynamically stable than the other phases. ${ }^{1)}$ The balance of the kinetic and thermodynamic stability to form PVDF crystalline phases can evolve with the variation of preparation conditions. Then, the evaporation rate in PVDF solutions prepared utilizing HMPA, DMAc and acetone as solvents was altered by controlling the evaporation conditions and quantified by measuring the sample weight alteration with the solvent evaporation time. ${ }^{14)}$ As a result, the crystalline structures of the $\operatorname{PVDF} \beta, \alpha$, and $\gamma$ phases were formed with evaporation rates of less than $0.0001 \mathrm{~g} / \mathrm{min}$, more than $0.2 \mathrm{~g} / \mathrm{min}$, and between 0.03 and $0.00058 \mathrm{~g} / \mathrm{min}$, respectively.

In the present study, we investigated the effect of the solvent properties on the PVDF crystal formation in the spin-coating process. The electrostatic interaction between the PVDF and the solvents is also important to the formation of the PVDF polymorphs. The relationship between the solvent properties and solvent evaporation conditions via the PVDF crystalline structure was considered. The PVDF crystalline structure varied with 
time during the evaporation process and was gradually evaluated for the consideration of the effect of the evaporation rate and solvent properties on the crystal nucleation and growth.

\section{Experimental procedure}

\section{Materials and reagents}

The PVDF was obtained from Kureha Co. (Tokyo, Japan), KF polymer \#1100 ( $M_{\mathrm{w}}$ : 280,000, homopolymer), and dried at $100{ }^{\circ} \mathrm{C}$ for 1 day before use. HMPA, DMAc, $N$-methyl pyrrolidone (NMP) and triethyl phosphate (TEP) were used as PVDF solvents without further purification.

\section{Preparation of the PVDF film by spin-coating}

PVDF was dissolved in HMPA, NMP, DMAc, and TEP at a concentration of $20 \mathrm{wt} \%$. The dissolution of each sample was performed at $25-200{ }^{\circ} \mathrm{C}$ for 1 day (HMPA, NMP, DMAc: $25^{\circ} \mathrm{C}$, TEP: $200{ }^{\circ} \mathrm{C}$ ). These solutions were coated onto a Si wafer at 500 r.p.m. for $20 \mathrm{~s}$ by a spin-coater (Active Co., ACT-300A). The Si wafers cast with each solution were dried at $40-160{ }^{\circ} \mathrm{C}$ under an ambient atmosphere on a hotplate (HMPA: 25,100 and $160{ }^{\circ} \mathrm{C}$, NMP: 40 and $100{ }^{\circ} \mathrm{C}$, DMAc: 40 and $100{ }^{\circ} \mathrm{C}$, TEP: 40 and $100{ }^{\circ} \mathrm{C}$ ). The 
evaporation rate of the samples was quantified by measuring the sample weight with an electronic balance. The residual amount of solvent in the PVDF film was quantified from the weight loss of the film as measured by TGA (Seiko Instruments, Inc., TG/DTA 6200). The films with various drying times were heated at $190{ }^{\circ} \mathrm{C}$ under a nitrogen atmosphere until the weight became constant, and the weight loss was defined by the residual amount of solvent.

The crystalline structures of the PVDF films were evaluated by FT-IR (Shimadzu Co., IR Prestige-21) and XRD (Rigaku Co., Mini Flex II). The crystalline structure was identified by referring to the standard samples of each crystalline structure. The preparation of the standard samples has been described in a previous study in detail ${ }^{13)}$. XRD measurements were performed using $\mathrm{Cu}-\mathrm{K} \alpha$ rays (wavelength $1.541841 \AA$, X-ray tube voltage of $30 \mathrm{kV}$ and direct current of $15 \mathrm{~mA}$ ), and the scanning rate was $2 \% \mathrm{~min}$ $(\theta-2 \theta)$. The infrared absorption bands and X-ray diffraction angles of the PVDF $\alpha, \beta$, and $\gamma$ phases are summarized in table $1^{13)}$.

Table 1. FT-IR bands and X-ray diffraction angles of PVDF $\alpha, \beta$ and $\gamma$ crystalline phases. 


\begin{tabular}{cccc}
\hline $\begin{array}{c}\text { Crystalline } \\
\text { phase }\end{array}$ & FT-IR & \multicolumn{2}{c}{ XRD } \\
\hline$\alpha$ & Wavenumber $\left(\mathrm{cm}^{-1}\right)$ & $2 \theta\left(^{\circ}\right)$ & Miller index \\
& $766\left(\mathrm{CF}_{2}\right.$ bending $)$ & 17.6 & $(100)$ \\
& $795\left(\mathrm{CH}_{2}\right.$ rocking $)$ & 18.3 & $(020)$ \\
& $976\left(\mathrm{CH}_{2}\right.$ twisting $)$ & 19.8 & $(110)$ \\
& $1210\left(\mathrm{CF}_{2}\right.$ antisymmetric & 26.5 & $(021)$ \\
$\quad$ stretching $)$ & & \\
$\beta$ & $840\left(\mathrm{CH}_{2}\right.$ rocking $)$ & 20.3 & $(110)(200)$ \\
& $1279\left(\mathrm{CF}_{2}\right.$ symmetric & & \\
& stretching $)$ & & \\
& $833\left(\mathrm{CF}_{2}\right.$ symmetric & 18.5 & $(020)$ \\
& stretching $)$ & 19.2 & $(002)$ \\
& $1234\left(\mathrm{CF}_{2}\right.$ antisymmetric & 20.0 & $(110)$ \\
& stretching $)$ & & \\
\hline
\end{tabular}

\section{Results and discussion}

Identification of crystalline structures of spin-coated PVDF films with solvent evaporation time

To consider the PVDF crystalline phase formation during the drying process after spin-coating, the correlation between the PVDF crystalline structure and the residual amounts of solvents was evaluated. The XRD patterns and FT-IR spectra of PVDF/HMPA, NMP, DMAc and TEP solution systems with various drying times and temperatures were measured. The PVDF/acetone solution system did not consider the evaporation conditions because PVDF only swells or partially dissolves in acetone near the boiling point. Figure 1 shows the XRD patterns and FT-IR spectra of the PVDF 
spin-coated Si-substrate using HMPA as a solvent, respectively. The drying conditions were $100{ }^{\circ} \mathrm{C}$ for $30,54,59$ and 1200 min, and the residual amounts of HMPA were 63 , 44, 34 and 1\%. The PVDF sample at $63 \%$ of the HMPA showed only the peak from the solvent in Figure 1a), and the peaks from the PVDF $\beta$ and $\gamma$ phases were slightly observed at approximately $840 \mathrm{~cm}^{-1}$ in Figure 1c). At $44 \%$ of the HMPA, the specific peak of the PVDF $\beta$ phase was confirmed at $20.7^{\circ}$ and the peaks from the PVDF $\beta$ and $\gamma$ phases were confirmed at $840 \mathrm{~cm}^{-1}$. By contrast, the PVDF samples at $34 \%$ and $1 \%$ of the solvent showed the specific peaks of the $\gamma$ phase at $20.3^{\circ}$ and $1234 \mathrm{~cm}^{-1}$. The PVDF crystalline structure changed with the amount of residual solvent, and the PVDF sample using HMPA as a solvent formed the $\beta$ phase at the initial stage of the drying process. The drying conditions were $160{ }^{\circ} \mathrm{C}$ for $2,3,6$ and $22 \mathrm{~min}$, and the residual amounts of HMPA were 71, 61, 34 and 0\%, respectively.

The XRD patterns and FT-IR spectra were similarly measured, as shown in Figures 1b) and 1d). The crystalline structures of the PVDF sample with residual amounts of HMPA of 71,61 and $34 \%$ were almost the same as those obtained at a $100{ }^{\circ} \mathrm{C}$ drying temperature. By contrast, the PVDF sample at $0 \%$ residual HMPA showed the specific peaks of the $\alpha$ phase at $17.8,18.7,19.8$ and $26.5^{\circ}$ in the XRD pattern and $766,795,974$, and $1210 \mathrm{~cm}^{-1}$ in the FT-IR spectrum. The PVDF sample using HMPA as a solvent at a 
$160{ }^{\circ} \mathrm{C}$ drying temperature also formed the $\beta$ phase at the initial stage of the drying process, and the PVDF crystalline structure changed in the order of amorphous, $\beta, \gamma$ and $\alpha$ phases with the decreasing residual amount of HMPA at 71, 61, 34 and $0 \%$.

From the above results, PVDF samples prepared by the spin-coating method using HMPA as a solvent formed a $\beta$ phase crystalline structure at the initial stage of the drying process, i.e., much HMPA remained in the PVDF film, regardless of the drying temperature, and the crystalline structure of PVDF using HMPA at the final stage, i.e., when the HMPA was completely evaporated from the film, the structure was dependently changed in the order of the $\beta, \gamma$, and $\alpha$ phases by altering the evaporation rate. It was anticipated that the alteration of the PVDF crystalline structure in the order of the $\beta, \gamma$, and $\alpha$ phases while evaporating the HMPA at $160{ }^{\circ} \mathrm{C}$ is due to the reduction of the electrostatic interactions between the PVDF and HMPA. The electrostatic interaction compensates for the intramolecular repulsion of the all-trans conformational structure in the $\beta$ phase, thus, the kinetically metastable $\beta$ phase was formed in the much-HMPA-remaining state. The crystalline transition from the $\beta$ to $\gamma$ phases occurred with decreasing amounts of HMPA. Finally, a kinetically stable $\alpha$ phase was formed in the almost-all-HMPA-evaporated state at $160{ }^{\circ} \mathrm{C}$. 

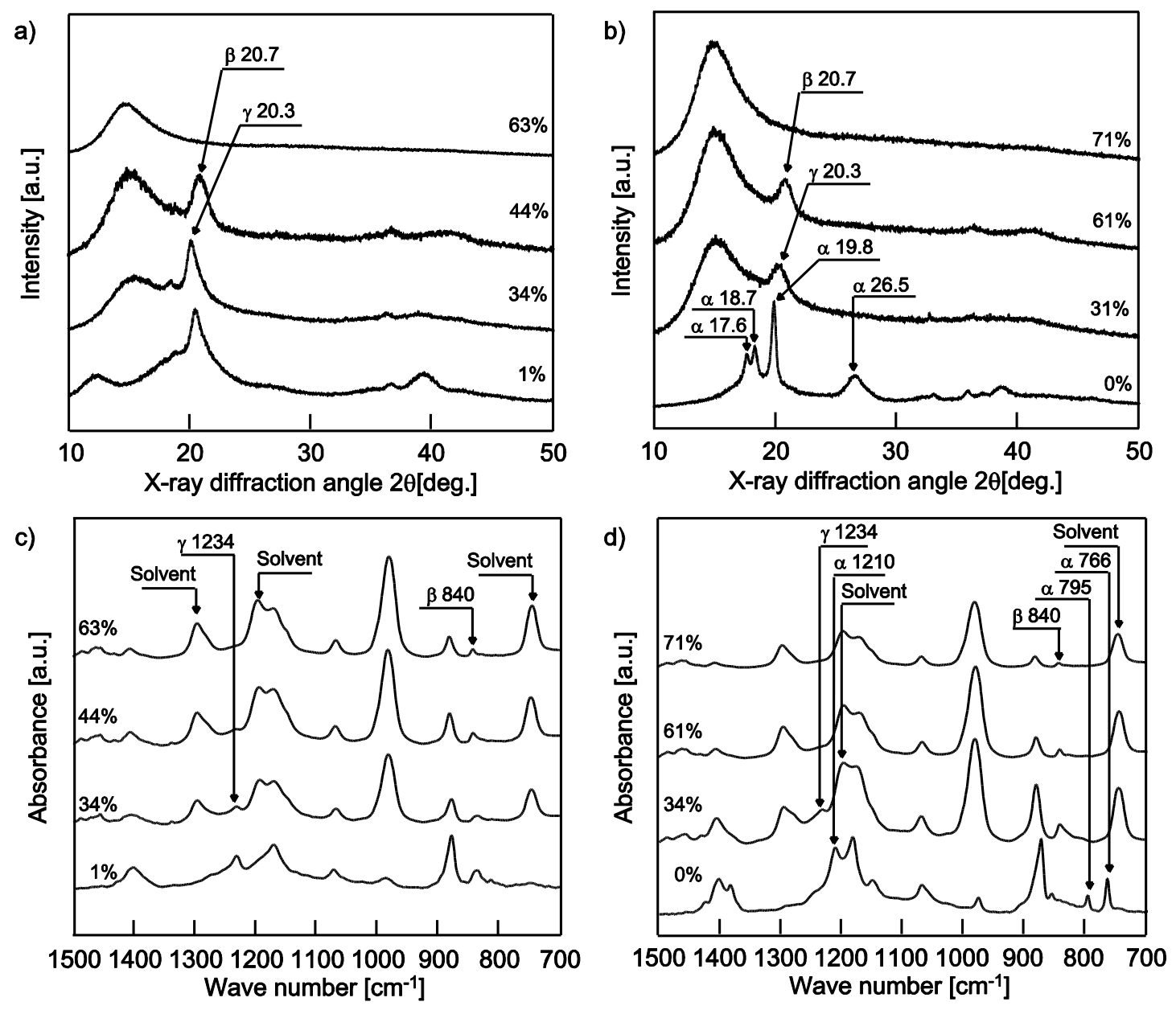

Figure 1. XRD patterns $(a, b)$ and FT-IR (c, d) spectra of PVDF film prepared using

HMPA as a solvent at $100{ }^{\circ} \mathrm{C}(\mathrm{a}, \mathrm{c})$ and $160{ }^{\circ} \mathrm{C}(\mathrm{b}, \mathrm{d})$ of evaporation temperatures. The percentages indicate the residual amounts of solvent.

The crystalline structures of PVDF using DMAc as a solvent with various drying times and temperatures were also measured by XRD patterns (Figures $2 \mathrm{a}$ ) and $2 \mathrm{~b}$ )) and FT-IR spectra (Figures 2c) and 2d)). The drying conditions in Figures 2a) and 2c) were a $40{ }^{\circ} \mathrm{C}$ drying temperature for several evaporation cycles. The specific peaks from the PVDF $\gamma$ 
phases at $20.0^{\circ}$ in the XRD pattern and at approximately 840 and $1234 \mathrm{~cm}^{-1}$ in the FT-IR spectrum were observed when more than $70 \%$ of the DMAc remained in the PVDF film. The peak at $1265 \mathrm{~cm}^{-1}$ was from residual DMAc, and it was difficult to confirm the peak from the PVDF $\beta$ phase at $1275 \mathrm{~cm}^{-1}$. From the above, the crystalline structure of the PVDF sample with residual amounts of DMAc greater than $70 \%$ is defined as having a $\gamma$ phase dominant structure. The peaks at $20.0^{\circ}$ and $1234 \mathrm{~cm}^{-1}$ from the $\gamma$ phase became clear with the decreasing residual amounts of DMAc, and no crystalline phase transition was confirmed with the different residual amounts of DMAc. At a $100{ }^{\circ} \mathrm{C}$ drying temperature, the crystalline structure of the PVDF sample with residual amounts of DMAc of approximately 50\% showed only the peak from the solvent in the XRD pattern (Figure 2b)), whereas the peaks from the PVDF $\gamma$ phases at approximately 840 and $1234 \mathrm{~cm}^{-1}$ were observed in the FT-IR spectrum (Figure 2d)). At approximately $30 \%$ of the residual amount of DMAc, peaks from the PVDF $\alpha$ phases clearly appeared at 18.3 and $19.9^{\circ}$ in the XRD pattern, the intensity of the peaks from the $\gamma$ phase was significantly decreased, and the specific peaks from the $\alpha$ phase at 766, 795,974 , and $1210 \mathrm{~cm}^{-1}$ were confirmed in FT-IR spectrum. The crystalline state of the PVDF sample using DMAc changed from the $\gamma$ phase to the $\alpha$ phase with the residual amount of DMAc below 30\%. In the case of using DMAc as a solvent, the crystalline 
structure of the PVDF samples formed a $\gamma$ phase at the initial stage of the drying process, regardless of the drying conditions, and at the final stage was dependently changed by altering the evaporation rate. The DMAc also electrostatically interacted with the PVDF, causing it to form the $\gamma$ phase at the initial stage of evaporation. At the final stage of evaporation, the crystalline transition from the $\gamma$ to $\alpha$ phase occurred with the decreasing amount of DMAc at a $100{ }^{\circ} \mathrm{C}$ evaporation temperature.

(a)

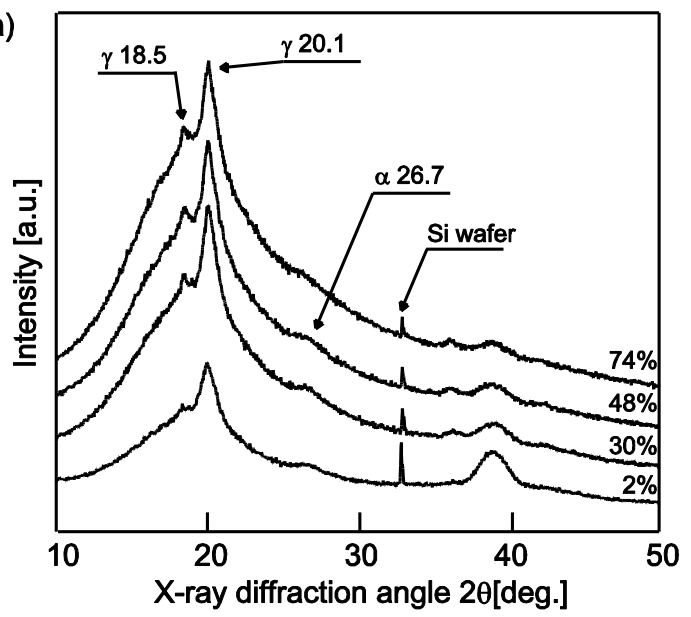

(c)

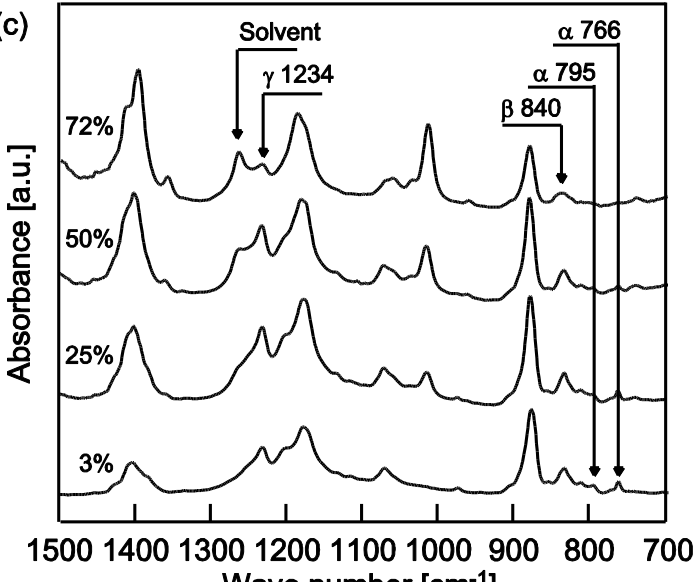

(b)

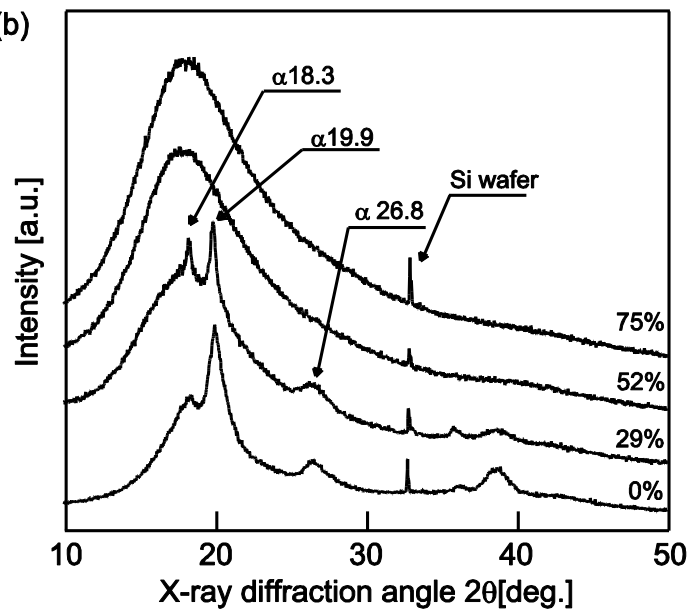

(d)

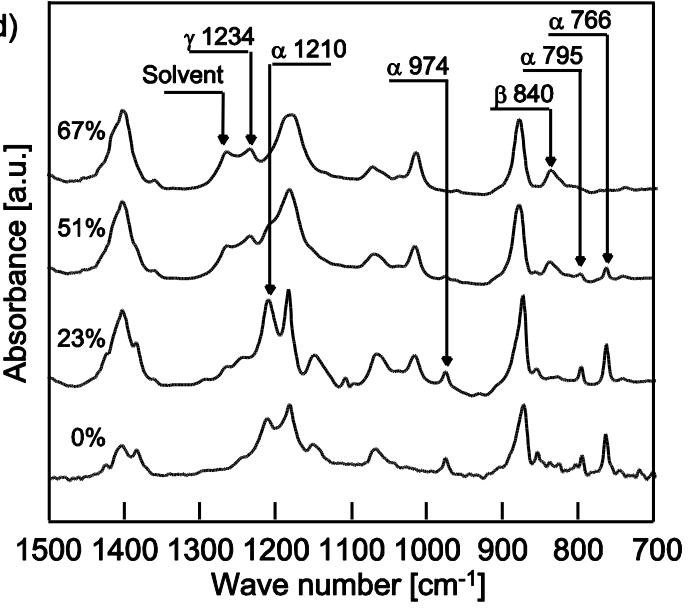


Figure 2. XRD patterns (a, b) and FT-IR (c, d) of PVDF film prepared using DMAc as a solvent at a $40{ }^{\circ} \mathrm{C}(\mathrm{a}, \mathrm{c})$ and $100{ }^{\circ} \mathrm{C}(\mathrm{b}, \mathrm{d})$ of evaporation temperatures. The percentages indicate the residual amounts of solvent.

Figures 3a), 3b), 3c) and 3d) show the XRD patterns and FT-IR spectra of PVDF samples using NMP as a solvent with various drying times and temperatures. In the case of $100 \%$ of the residual amount of NMP before drying, no specific peaks from the PVDF crystalline phases were observed. The PVDF sample with approximately $70 \%$ of the residual amount of NMP showed slight peaks from the PVDF $\gamma$ phases at $20.1^{\circ}$ in the XRD pattern. The PVDF sample at approximately 50\% showed the peaks from the $\gamma$ and $\alpha$ phases at 18.3 and $20.1^{\circ}$ in the XRD pattern and 766, 795, 840, 1210 and 1234 $\mathrm{cm}^{-1}$ in the FT-IR spectra. The intensity of the binary peaks from the $\gamma$ and $\alpha$ phases increased with decreasing the residual amount of NMP below 50\%. The crystalline structure of the PVDF sample using NMP with a $40{ }^{\circ} \mathrm{C}$ drying temperature formed a $\gamma$ and $\alpha$ phase mixed structure at the first and final stages. At a $100{ }^{\circ} \mathrm{C}$ drying temperature in Figures 3b) and 3d), the peaks from the PVDF crystalline phases were not confirmed at approximately $70 \%$ of the residual amount of NMP. The peaks from the $\gamma$ and $\alpha$ phases at 766, 795, 840, 1210 and $1234 \mathrm{~cm}^{-1}$ in the FT-IR were observed in the sample 
at $53 \%$ of the residual amount of NMP. However, in the PVDF samples with residual amounts of NMP below $21 \%$, the peak disappeared from the $\gamma$ phase, the intensity of the peaks from the $\alpha$ phase at 766, 795, and $1210 \mathrm{~cm}^{-1}$ in the FT-IR increased, and peaks from the $\alpha$ phase in the XRD at $18.3,19.9$ and $26.8^{\circ}$ appeared. In the case of NMP as a solvent, the crystalline structure of the PVDF samples formed a $\gamma$ and $\alpha$ phase mixed structure at the initial stage of the drying process, regardless of the drying conditions, and that at the final stage varied with the evaporation rate.

(a)

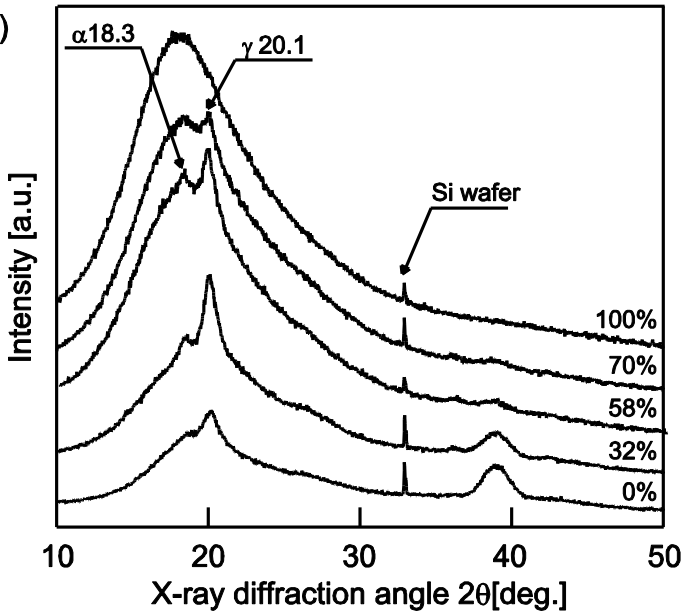

(c)

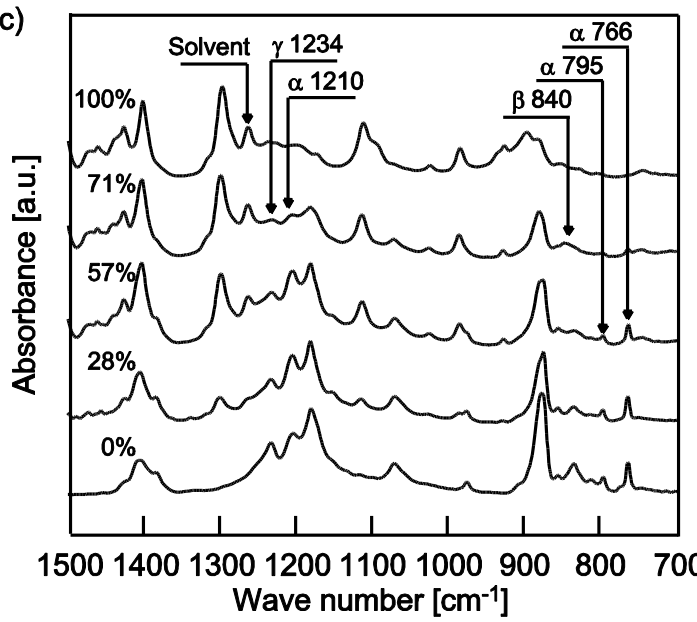

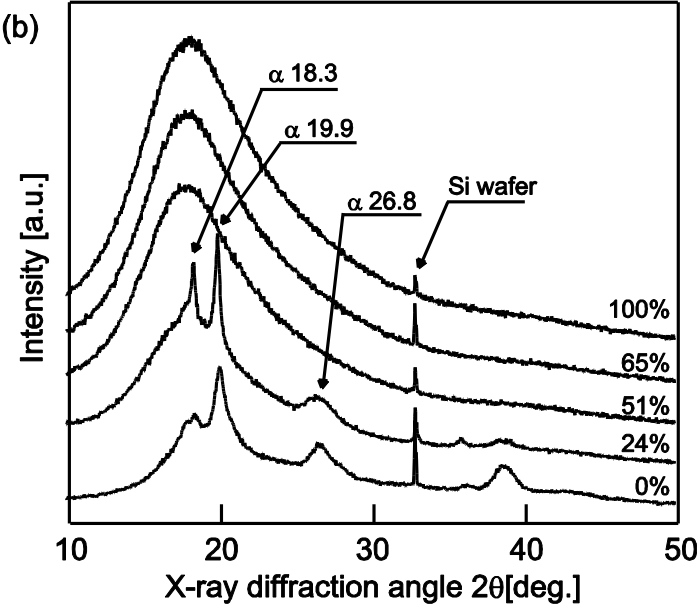

(d)

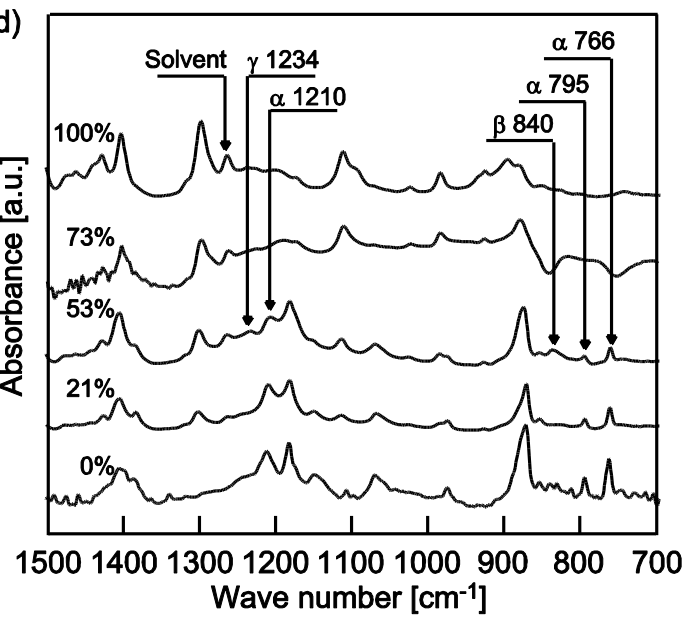


Figure 3. XRD patterns (a, b) and FT-IR (c, d) of PVDF film prepared using NMP as a solvent at a $40{ }^{\circ} \mathrm{C}(\mathrm{a}, \mathrm{c})$ and $100{ }^{\circ} \mathrm{C}(\mathrm{b}, \mathrm{d})$ of evaporation temperatures. The percentages indicate the residual amounts of solvent.

Finally, the XRD patterns and FT-IR spectra of PVDF samples using TEP as a solvent with various drying times and 40 and $100{ }^{\circ} \mathrm{C}$ drying temperatures are shown in Figures 4a), 4b), 4c) and 4d). At 100\% of the residual amount of TEP before drying, no specific peaks from the PVDF crystalline phases were observed, while the PVDF sample at approximately $50 \%$ of the residual amount of TEP showed peaks from the $\alpha$ phase at 18.3, 19.9 and $26.8^{\circ}$ in the XRD pattern (Figure 4a)) and at 766 and $1210 \mathrm{~cm}^{-1}$ in the FT-IR (Figure 4c)). The crystalline structure of the PVDF sample using TEP at a $40{ }^{\circ} \mathrm{C}$ drying temperature showed only the $\alpha$ phase at the first and final stages of the drying process. Furthermore, the case at a $100{ }^{\circ} \mathrm{C}$ drying temperature was almost the same as those obtained at $40{ }^{\circ} \mathrm{C}$ (Figures $4 \mathrm{~b}$ ) and $4 \mathrm{~d}$ )). Consequently, the crystalline structures of the PVDF samples using TEP as a solvent formed only the $\alpha$ phase at the first and final stages, regardless of the evaporation rate. The electrostatic interaction between PVDF and TEP is lower, resulting in the formation of the PVDF $\alpha$ phase. 
(a)

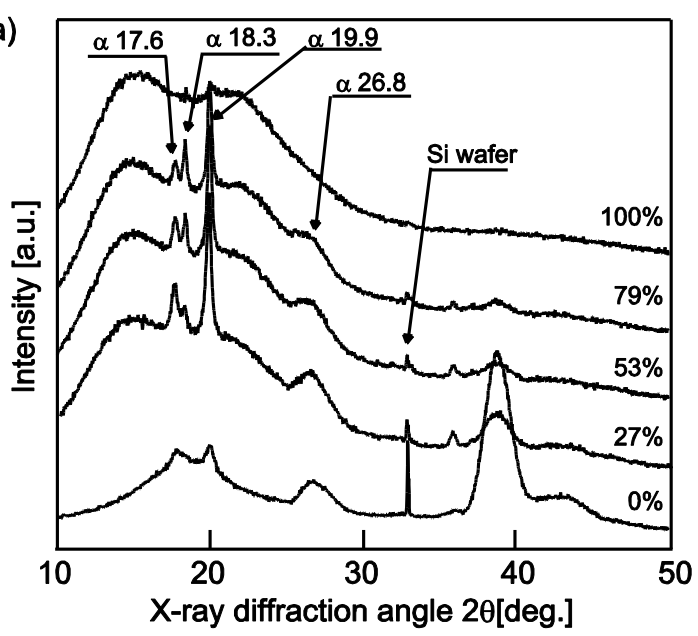

(c)

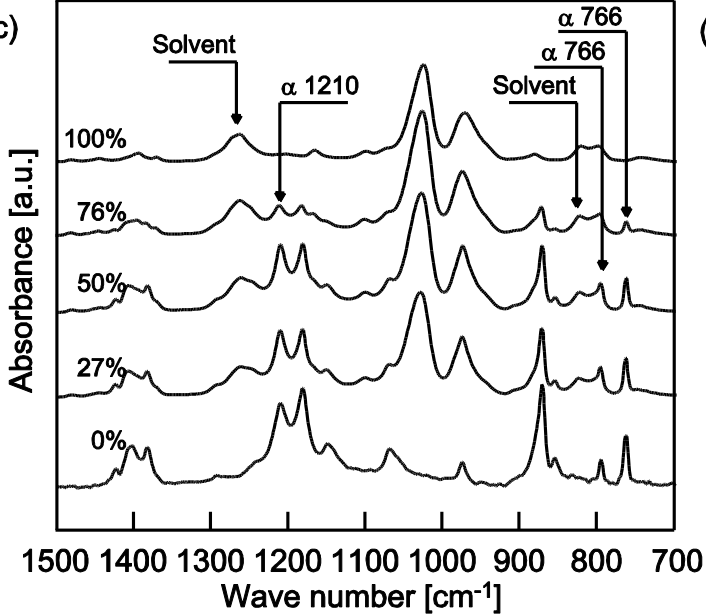

(b)
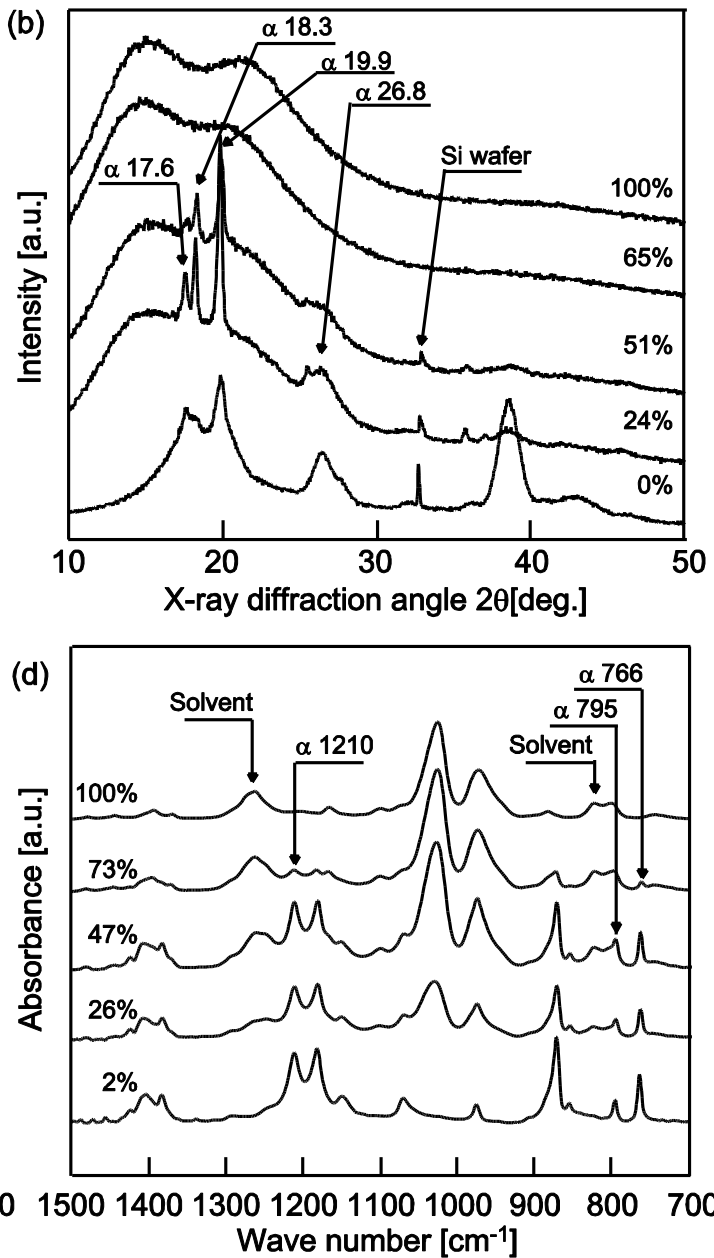

Figure 4. XRD patterns $(a, b)$ and FT-IR $(c, d)$ of PVDF film prepared using TEP as a solvent at a $40{ }^{\circ} \mathrm{C}(\mathrm{a}, \mathrm{c})$ and $100{ }^{\circ} \mathrm{C}(\mathrm{b}, \mathrm{d})$ of evaporation temperatures. The percentages indicate the residual amounts of solvent.

Effect of solvents on the formation of PVDF crystalline phases at various drying conditions in the spin-coating process 
Table 2. PVDF crystalline structures at the first and final stages of the evaporation process.

\begin{tabular}{crrccc}
\hline \multirow{2}{*}{ Solvent } & Temperature & Drying rate & \multicolumn{2}{c}{ Crystalline structure } & Dipole moment \\
& $\left({ }^{\circ} \mathrm{C}\right)$ & $(\mathrm{mg} / \mathrm{min})$ & Initiala $^{\mathrm{a})}$ & Final $^{\mathrm{b})}$ & $(D)$ \\
\hline HMPA & 25 & 0.02 & $\beta$ & $\beta$ & $4.31^{15)}$ \\
HMPA & 100 & 30 & $\beta$ & $\gamma$ & $4.31^{15)}$ \\
HMPA & 160 & 280 & $\beta$ & $\alpha$ & $4.31^{15)}$ \\
NMP & 40 & 5 & $\gamma$ & $\gamma$ & $4.06^{16)}$ \\
NMP & 100 & 90 & $\gamma$ & $\alpha$ & $4.06^{16)}$ \\
DMAC & 40 & 28 & $\gamma$ & $\gamma$ & $3.72^{17)}$ \\
DMAC & 100 & 330 & $\gamma$ & $\alpha$ & $3.72^{17)}$ \\
TEP & 40 & 4 & $\alpha$ & $\alpha$ & $3.07^{18)}$ \\
TEP & 100 & 110 & $\alpha$ & $\alpha$ & $3.07^{18)}$ \\
\hline
\end{tabular}

a) PVDF concentrated solution or PVDF film containing a solvent enough

b) Solvents were almost not remained

The above results at the initial and final stages of the drying process are summarized in

Table 2. Then, focusing on the results of the initial stage, the PVDF crystalline phase changed with the solvent even if the evaporation rate was almost the same, e.g., HMPA, $100{ }^{\circ} \mathrm{C}, 30 \mathrm{mg} / \mathrm{min}$ versus DMAc, $40{ }^{\circ} \mathrm{C}, 28 \mathrm{mg} / \mathrm{min}$. At the initial stage of the drying process on spin-coating, no correlation between the crystalline structure and evaporation rate was identified. We thus expected that the difference in the electrostatic interactions between the PVDF chain and the solvents would induce a crystalline phase transition in the initial stage of the drying process, and we focused on the relationship between the crystalline phase at the initial stage and the dipole moment of the solvents. 
The dipole moments of HMPA, NMP, DMAc and TEP are 4.31 ${ }^{15)}, 4.06^{16)}, 3.72^{17)}$, and $3.07 \mathrm{D}^{18)}$, respectively, as shown in the rightmost column of Table 2 . The crystalline structures of the PVDF samples at the initial stage of the drying process changed in the order of the $\alpha, \gamma$, and $\beta$ phases with the increasing dipole moment of the solvents. When HMPA having a higher dipole moment was used as a solvent for the PVDF, the crystalline structure of the PVDF sample at the initial stage of the drying process was the $\beta$ phase. When TEP, having a lower dipole moment, was used as a solvent for PVDF, the crystalline structure of the PVDF sample at the initial stage of the drying process was the $\alpha$ phase. When NMP and DMAc, having dipole moments between those of HMPA and TEP, were used as solvents for PVDF, the crystalline structure of the PVDF sample at the initial stage of the drying process was a $\gamma$-dominated mixture of phases. These results suggest that the electrostatic interaction between the PVDF and the solvents dramatically affected the crystalline structure of the PVDF samples at the initial stage of the drying process. PVDF has a permanent dipole moment of 2.1 Debye per monomer unit in the $\beta$ phase and 1.3 Debye in the $\alpha$ phase ${ }^{19)}$. When PVDF is solvated by a solvent having a high dipole moment, it interacts with the solvent, and the higher electrostatic interaction would induce locally extended chain coil formation. Therefore, PVDF in a solvent having a higher dipole moment easily formed the 
all-trans conformation, i.e., the $\beta$ phase. When PVDF is solvated by a solvent having a low dipole moment, the solvent has little interaction with the PVDF, and the PVDF chain would form unexpanded or shrunken globules. Thus, the PVDF in a solvent having a lower dipole moment easily formed the twist conformation, i.e., the $\alpha$ phase.

Next, focusing on the final stage of the drying process, the PVDF crystalline phase was dominantly dependent on the evaporation rate. The crystalline structure of the PVDF film varied in the order of $\alpha, \gamma$, and $\beta$ with the decreasing solvent evaporation rate. The results assumed that the interaction between the PVDF chain and the solvents was reduced by an increase in the chain mobility due to the higher drying temperature. It has been reported that the PVDF crystalline phases or mixture contents in the $\beta, \gamma$ and $\alpha$ phases vary at different isothermal crystallization temperatures ${ }^{20)}$. The crystalline phase transition in the order of the $\beta, \gamma$ and $\alpha$ phases is correlated with the potential energy of each PVDF crystalline phase. The potential energy of the $\beta$ phase is higher than that of the $\gamma$ and $\alpha$ phases, and thus the $\beta$ phase is metastable and can easily transform to the $\gamma$ and $\alpha$ phases. In contrast, the PVDF crystalline phase in the case of TEP did not depend on the drying temperature because TEP has little interaction with the PVDF polar structure. The PVDF sample using TEP as a solvent formed the $\alpha$ phase in mild conditions of the drying process. The PVDF $\alpha$ phase is stable in terms of 
potential energy, and it would be difficult to transform into the $\beta$ and $\gamma$ phases.

From the results of the initial and final stages, the $\gamma$ phase was consistently formed at the intermediate condition of the $\beta$ and $\alpha$ phases. Consequently, it was anticipated that the potential energy of the $\gamma$ phase would be between those of the $\beta$ and $\alpha$ phases, and the potential energy of the PVDF crystalline structure was higher in the order of the $\alpha, \gamma$ and $\beta$ phases. Figure 5 shows the correlation between the polymer-solvent interaction and evaporation rate against the PVDF crystalline structure. A metastable $\beta$ phase with a higher potential energy was formed in solvents having a higher dipole moment and can easily transform into the intermediate $\gamma$ and stable $\alpha$ phases with a lower potential energy under evaporation conditions. The $\gamma$ phase with an intermediate potential energy of the $\beta$ and $\alpha$ phases can easily transform into the stable $\alpha$ phase by evaporation conditions but cannot easily transform into the metastable $\beta$ phase with a higher potential energy. The stable $\alpha$ phase with a lower potential energy was formed in solvents having a lower dipole moment and could not easily transform to the metastable $\beta$ and intermediate $\gamma$ phases with higher potential energy. The potential energy for each PVDF crystalline structure was calculated with density functional theory by optimizing the atomic position and cell parameter, and it assumed the order of the $\alpha, \gamma$ and $\beta$ phases $^{21)}$. The simulation is in good agreement with the crystalline transition behavior 
as described above. The results of the crystalline transition behavior experimentally supported the hypothesis that the potential energy of the PVDF crystalline structure is higher in the order of $\alpha, \gamma$, and $\beta$.

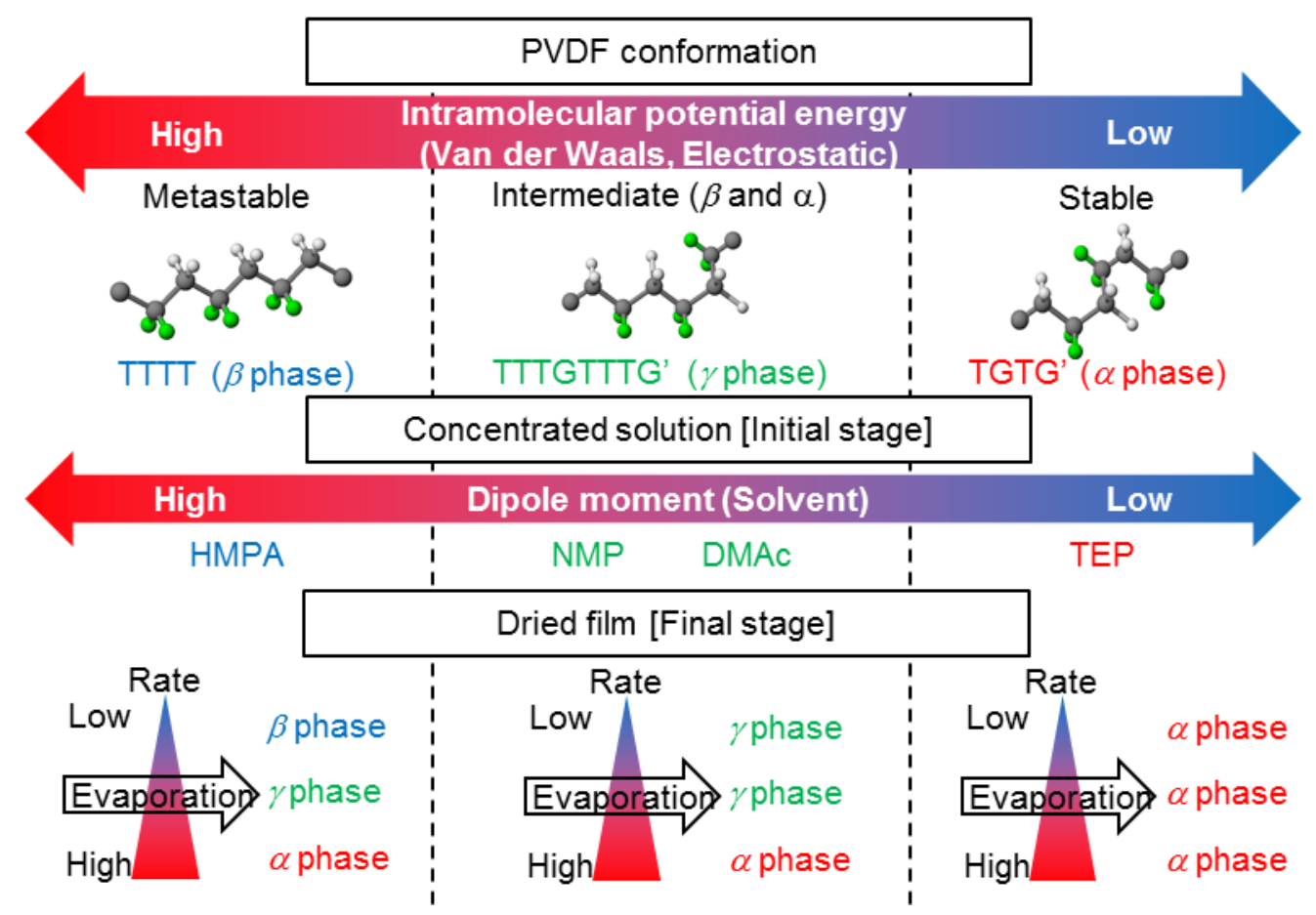

Figure 5. Correlation between polymer-solvent interactions and evaporation rate against

PVDF crystalline structure.

\section{Conclusions}

In the initial stage of the evaporation process after spin-coating, i.e., the much-solvent-remaining state, the crystalline structure of PVDF was correlated with the 
type of solvent. The crystalline phase in the initial stage changed in the order of $\alpha, \gamma$, and $\beta$ with the increasing dipole moment of the solvent: HMPA, having a higher dipole moment, induced the formation of the PVDF $\beta$ phase; TEP, having a lower dipole moment, induced the formation of the PVDF $\alpha$ phase; and DMAc and NMP, having intermediate dipole moments, induced the formation of the $\gamma$ phase, which is an intermediate structure between the $\beta$ and $\alpha$ phases. In the final stage of evaporation, i.e., the almost-all-solvent evaporated state, the PVDF crystalline phase was dominantly dependent on the evaporation rate and varied in the order of $\alpha, \gamma$, and $\beta$ with the decreasing solvent evaporation rate. The PVDF samples using TEP as a solvent consistently formed the $\alpha$ phase, regardless of the amount of residual solvent. The metastable $\beta$ phase was formed in solvents having a higher dipole moment and can easily transform into the intermediate $\gamma$ and stable $\alpha$ phases by evaporation. However, the stable $\alpha$ phase was difficult to transform to the metastable $\beta$ and intermediate $\gamma$ phases. The crystalline transition behavior experimentally supports the concept that the potential energy of each crystalline phase is higher in the order of the $\alpha, \gamma$, and $\beta$ phases. At the first and final stages of the evaporation process, the formation of the PVDF crystalline phases in the solvent evaporation method, especially the formation of the $\beta$ phase, strongly affects both the polymer-solvent interaction and the evaporation rate. 


\section{References}

1. Hasegawa R., Kobayashi M. \& Tadokoro H., "Molecular Conformation and Packing of Poly(vinylidene fluoride). Stability of Three Crystalline Forms and the Effect of High Pressure”, Polym. J., 3, 591 (1972)

2. Hasegawa R., Takahashi Y., Chatani Y. \& Tadokoro H., "Crystal Structures of Three Crystalline Forms of Poly(vinylidene fluoride)", Polym. J., 3, 600 (1972)

3. Davis G. T., McKinney J. E., Broadhurst M. G. \& Roth S. C., "Electric-Field-Induced Phase Changes in Poly(vinylidene fluoride)", J. Appl. Phys., 49, $4998(1978)$

4. Gregorio R. \& Cestari M., "Effect of Crystallization Temperature on the Crystalliene Phase Content and Morphology of Poly(vinylidene fluoride)", J. Polym. Sci. B: Polym. Phys., 32, 859 (1994)

5. Benz M., Euler W. B. \& Gregory O. J., "The Role of Solution Phase Water on the Deposition of Thin Films of Poly(vinylidene fluoride)", Macromolecules, 35, 2682 (2002)

6. Cardoso V. F., Minas G., Costa C. M., Tavares C. J., Lanceros-Mendez S.. "Micro and Nanofilms of Poly(vinylidene fluoride) with Controlled Thickness, Morphology and Electroactive Crystalline Phase for Sensor and Actuator Applications", Smart Mater. 
Struct., 20, 087002 (2011)

7. Ramasundaram S., Yoon S., Kim K. J. \& Lee J. S., “Direct Preparation of Nanoscale Thin Films of Poly(vinylidene fluoride) Containing $\beta$-Crystalline Phase by Heat-Controlled Spin Coating”, Macromol. Chem. Phys., 209, 2516 (2008)

8. Li M., Wondergem J. H, Spijkman M. J., Asadi K., Katsouras I, Blom W. M. P. \& de Leeuw M. D., "Revisiting the $\delta$-Phase of Poly(vinylidene fluoride) for Solution-Processed Ferroelectric Thin Films", Nat. Mater., 12, 433 (2013)

9. Nasir M., Matsumoto H., Minagawa M., Tanioka A., Danno T. \& Horibe H., "Preparation of PVDF/PMMA Blend Nanofibers by Electrospray Deposition: Effects of Blending Ratio and Humidity", Polym. J., 41, 402-406 (2009)

10. Danno T., Nasir M., Matsumoto H., Minagawa M., Tanioka A. \& Horibe H., "Fine Structure of PVDF Nanofiber Fabricated by Electrospray Deposition", J. Polym. Sci., B: Polym. Phys., 46, 558-563 (2008)

11. Nasir M., Matsumoto H., Minagawa M., Tanioka A., Danno T. \& Horibe H., "Preparation of Porous PVDF Nanofiber from PVDF/PVP Blend by Electrospray Deposition”, Polym. J., 39, 1060-1064(2007)

12. Nasir M., Matsumoto H., Minagawa M., Tanioka A., Danno T. \& Horibe H., "Formation of $\beta$-Phase Crystalline Structure of Nanofiber by Electrospray Deposition: 
Additive Effect of Ionic Fluorinated Surfactant”, Polym. J., 39, 670-674(2007)

13. Kobayashi M., Tashiro K. \& Tadokoro H., "Molecular Vibrations of Three Crystal Forms of Poly(vinylidene fluoride)", Macromolecules, 8, 158(1975)

14. Horibe H., Sasaki Y., Oshiro H., Hosokawa Y., Kono A., Takahashi S. \& Nishiyama T., "Quantification of the solvent evaporation rate during the production of three PVDF crystalline structure types by solvent casting", Polym. J., 46, 104(2014)

15. Normant H., "Hexamethylphosphoramide", Angew. Chem. Int. Ed. Engl., 6, 1046 (1967)

16. Lee M. C. \& Kumler D. W., "The Dipole Moment and Structure of Five- and Six-Membered Lactams”, J. Am. Chem. Soc., 83, 4593 (1961)

17. Riddick A. J. \& Bunger B. W., Organic Solvents 3rd edn, 450 (Wiley-interscience, New York, NY, USA, 1970)

18. Svirbely W. J. \& Lander J. J., "The Dipole Moments of Diethyl Sulfite, Triethyl Phosphate and Tetraethyl Silicate", J. Am. Chem. Soc., 70, 4121 (1948)

19. Duan C., Mei N. W., Yin G. W., Liu J., Hardy R. J., Ducharme S. \& Dowben A. P., "Simulations of Ferroelectric Polymer Film Polarization: The Role of Dipole Interactions", Phys. Rev. B, 69, 235106 (2004)

20. Salimi A. \& Yousefi A. A., "Conformational Changes and Phase Transformation 
Mechanisms in PVDF Solution-Cast Films", J. Polym. Sci., B: Polym. Phys., 42, 3487 (2004)

21. Su H., Strachan A., and Goddard III A. W., "Density Functional Theory and Molecular Dynamics Studies of the Energetics and Kinetics of Electroactive Polymers: PVDF and P(VDF-TrFE)", Phys. Rev. B, 70, 064101 (2004)

\section{Figure Legends}

Figure 1. XRD patterns (a, b) and FT-IR (c, d) spectra of PVDF film prepared using HMPA as a solvent at $100{ }^{\circ} \mathrm{C}(\mathrm{a}, \mathrm{c})$ and $160{ }^{\circ} \mathrm{C}(\mathrm{b}, \mathrm{d})$ of evaporation temperatures. The percentages indicate the residual amounts of solvent.

Figure 2. XRD patterns $(a, b)$ and FT-IR (c, d) of PVDF film prepared using DMAc as a solvent at a $40{ }^{\circ} \mathrm{C}(\mathrm{a}, \mathrm{c})$ and $100{ }^{\circ} \mathrm{C}(\mathrm{b}$, d) of evaporation temperatures. The percentages indicate the residual amounts of solvent.

Figure 3. XRD patterns $(a, b)$ and FT-IR (c, d) of PVDF film prepared using NMP as a solvent at a $40{ }^{\circ} \mathrm{C}(\mathrm{a}, \mathrm{c})$ and $100{ }^{\circ} \mathrm{C}(\mathrm{b}, \mathrm{d})$ of evaporation temperatures. The percentages indicate the residual amounts of solvent.

Figure 4. XRD patterns $(a, b)$ and FT-IR $(c, d)$ of PVDF film prepared using TEP as a solvent at a $40{ }^{\circ} \mathrm{C}(\mathrm{a}, \mathrm{c})$ and $100{ }^{\circ} \mathrm{C}(\mathrm{b}, \mathrm{d})$ of evaporation temperatures. The percentages 
indicate the residual amounts of solvent.

Figure 5. Correlation between polymer-solvent interactions and evaporation rate against PVDF crystalline structure.

Table 1. FT-IR bands and X-ray diffraction angles of PVDF $\alpha, \beta$ and $\gamma$ crystalline phases.

Table 2. PVDF crystalline structures at the first and final stages of the evaporation process. 